\title{
Heat Shock Protein 27 Expression in EUS-FNA Samples Can Predict Gemcitabine Sensitivity in Pancreatic Cancer
}

\author{
MICHITAKA KAWANO, SEIJI KAINO, SHOGO AMANO, SHUHEI SHINODA, \\ SHIGEYUKI SUENAGA, MANABU SEN-YO and ISAO SAKAIDA \\ Department of Gastroenterology and Hepatology, \\ Yamaguchi University Graduate School of Medicine, Yamaguchi, Japan
}

\begin{abstract}
Background/Aim: Gemcitabine (GEM) sensitivity can help select the appropriate treatment for pancreatic cancer. We examined the association between HSP27 expression and GEM sensitivity. Materials and Methods: A total of 19 patients with unresectable pancreatic cancer who underwent endoscopic ultrasonography-guided fine needle aspiration (EUS-FNA) were enrolled and treated with GEM alone. We measured the expression of heat shock protein 27 (HSP27) and phosphorylated HSP27(p-HSP27) in EUS-FNA samples and evaluated the effects of GEM treatment. Results: The rate of GEM resistance was significantly higher in patients who showed overexpression of p-HSP27 $(p<0.05)$. When we set the cut-off p-HSP27 (Ser82) detection rate at $51.6 \%$, the group with a detection rate of $>51.6 \%$ showed a significantly lower survival rate, and GEM was administered for a shorter period of time $(p<0.05)$. Conclusion: It was suggested that the HSP27 expression in EUS-FNA samples was useful for predicting GEM sensitivity.
\end{abstract}

Pancreatic cancer shows one of the worst prognoses among all malignant tumors since it progresses quickly and is difficult to diagnose at an early stage. Advances in chemotherapy are considered to be important for improving the prognosis of unresectable cases.

Burris et al. (1) reported that gemcitabine (GEM) can significantly prolong survival in comparison to 5-FU for unresectable pancreatic cancer. Recently, FOLFIRINOX (L-OHP, CPT-11, 5-FU, LV) therapy (2) and GEM combined

This article is freely accessible online.

Correspondence to: Michitaka Kawano, Department of Gastroenterology and Hepatology, Yamaguchi University Graduate School of Medicine, 1-1-1 Minami-Kogushi, Ube, Yamaguchi, Japan 755-(8505). Tel: +81 836852000, e-mail: mkawano0606@yahoo.co.jp.

Key Words: Pancreatic cancer, heat shock protein 27, gemcitabine, endoscopic ultrasonography-guided-fine needle aspiration. with nab-paclitaxel therapy (3) were shown to prolong survival. FOLFIRINOX was associated with strong toxicity, because it has not been established whether the combination therapy can be safely administered. It is thought that GEM based-chemotherapy will also be a key to the treatment of unresectable pancreatic cancer. It has been reported that recent advances in genetic analysis technology have revealed the factors involved with GEM sensitivity in pancreatic cancer cells $(4,5)$, and tailored therapies are expected.

We identified GEM resistance-related proteins in pancreatic cancer by a proteomic analysis. We compared the expression levels of proteins in GEM-resistant pancreatic cancer cell lines with the expression in GEM-sensitive cell lines using twodimensional electrophoresis and liquid chromatography-mass spectrometry. Among them, the expression of Heat shock protein 27 (HSP27) was found to be increased in the GEMresistant cell line. Furthermore, we confirmed that GEM sensitivity was restored when the HSP27 expression in the GEM-resistant cell line was reduced $(6,7)$. Additionally, we clarified that the expression of phosphorylated HSP27 (pHSP27) increased in the GEM-resistant cell line (8).

In addition, the ability to predict the treatment effects using endoscopic ultrasonography-guided fine needle aspiration (EUS-FNA) samples may help in the selection of appropriate medicines for unresectable pancreatic cancer.

No previous studies have evaluated the rates of HSP27 and p-HSP27 expression in pancreatic cancer cells from EUS-FNA samples. The purpose of this study was to evaluate the rates of HSP27 and p-HSP27 expression in EUS-FNA samples, and to demonstrate their association with GEM sensitivity.

\section{Materials and Methods}

Subjects, Examination items

The comparison of the rates of HSP27 expression in the EUS-FNA samples and the resected specimens. We compared the rates of HSP27 expression in EUS-FNA samples and resected specimens and evaluated the relationship with the resected specimens. The study population included 19 patients who had been diagnosed with 
pancreatic cancer by EUS-FNA and who underwent surgery between September 2010 and November 2013. We examined the correlation between the rates of HSP27 expression in the EUS-FNA samples and the resected specimens.

The comparison of the rates of HSP27 and p-HSP27 expression in EUS-FNA samples and GEM sensitivity. Among the patients with unresectable pancreatic cancer in whom EUS-FNA was performed from January 2007 to September 2014, the 19 patients who were treated with GEM monotherapy as a primary therapy were selected. We evaluated the rates of HSP27 and p-HSP27 expression in EUS-FNA samples and assessed the presence or absence of GEM sensitivity.

\begin{abstract}
Methods
Immunohistochemistry. We used a VECTASTAIN ABC kit (VECTOR Laboratories company, Burlingame, California, USA), which is an enzyme immunoassay. Tissue sections (3- $\mu$ m-thick) were deparaffinized in xylene and hydrated in alcohol. We heated the sections to $97^{\circ} \mathrm{C}$ in $0.01 \mathrm{~mol} / 1$ sodium citrate buffer for five minutes to activate the antigens. We incubated it in a methanol solution mixed with $0.3 \%$ hydrogen peroxide at normal temperature for 30 minutes and inactivated the endogenic enzyme activity. We dribbled normal animal serum with the adjusted secondary antibody and blocked the nonspecific binding of the primary antibody. We added the primary antibody, corresponding to the antigen, in a drop-wise manner and incubated the specimens at $4^{\circ} \mathrm{C}$ for $24 \mathrm{~h}$. Afterwards, biotin-labeled secondary antibodies were added; a conjugate of biotin and primary and secondary antibodies was formed. We added the avidin-biotinlabeled enzyme complex, which bound to a biotin-labeled secondary antibody. Lastly, an enzyme substrate solution was added and staining was performed. As post-processing, we counterstained the cross section with hematoxylin. The specimens were then dehydrated with alcohol, infiltrated with xylene and set in diaphane. Mouse anti-HSP27 monoclonal (Santa Cruz Biotechnology, F-4: sc-13132, Dallas, Texas, USA) and rabbit anti-phosphorylated HSP27 antibodies (Abcam, Ser15: ab39399, Ser78: ab32501, Ser82: ab155987, Cambridge, Massachusetts, USA) were used as the specific antibodies.
\end{abstract}

Methods of evaluation. The tumor cells in which the cytoplasm was stained brown were considered to express the specific antibody (HSP27 or p-HSP27). The specimens were examined under a microscope at $400 \times$ magnification and the ratio of positively stained tumor cells to the total number of cells was determined. The results indicate the average of the 3 fields that showed the highest number of positively stained cells.

The treatment effects of GEM. There were assessed in accordance with RECIST (9) - were assessed by CT after more than one course of GEM had been administered. Patients with GEM sensitivity were considered to have stable disease (SD); and patients with GEM resistance were considered to have progressive disease (PD).

Statistical analysis. The correlation of the HSP27 detection rates of the EUS-FNA samples and the resected specimens was determined using Spearman's rank correlation coefficient. Fisher's exact test and Student's $t$-test were used to compare the results of two groups. Based on the HSP27 detection rates, the optimal cut-off value for detecting the presence or absence of GEM sensitivity was determined by a receiver operating characteristic (ROC) curve analysis. The Kaplan-Meier method was used to analyze the
Table I. Background of the 19 patients who underwent EUS-FNA and surgery.

\begin{tabular}{lc}
\hline & $\mathrm{n}=19$ \\
\hline Gender, M/F & $8 / 11$ \\
Mean age $\pm \mathrm{SD}, \mathrm{y}$ & $66.8 \pm 10.4$ \\
Location, $\mathrm{Ph} / \mathrm{Pbt}$ & $16 / 3$ \\
Tumor size $\pm \mathrm{SD}, \mathrm{mm}$ & $21.7 \pm 6.8$ \\
Staging IA/IB/IIB/III/IV & $1 / 2 / 9 / 4 / 3$ \\
\hline
\end{tabular}

Table II. Background of the 19 patients who were treated with GEM monotherapy.

\begin{tabular}{lc}
\hline & $\mathrm{n}=19$ \\
\hline Gender, M/F & $5 / 14$ \\
Mean age $\pm \mathrm{SD}, \mathrm{y}$ & $69 \pm 8.4$ \\
Location, $\mathrm{Ph} / \mathrm{Pbt}$ & $5 / 14$ \\
Performance status, 0/1 & $16 / 3$ \\
Tumor size $\pm \mathrm{SD}, \mathrm{mm}$ & $47.4 \pm 20.7$ \\
Staging & \\
T 3/4 & $1 / 18$ \\
M 0/1 & $5 / 14$ \\
Effects of GEM, SD/PD & $6 / 13$ \\
\hline
\end{tabular}

survival rate and the percentage of patients who continued GEM treatment according to the HSP27 detection rate. The JMP 12 software program (SAS Institute Inc., Cary, North Carolina, USA) was used for the statistical analyses. $p$-Values of $<0.05$ were considered to indicate statistical significance.

\section{Results}

The comparison of the HSP27 detection rates of EUS-FNA samples and resected specimens. Patient background. The background information of all 19 patients is shown in Table I. The mean age was $66.8 \pm 10.4$ years, 8 of the patients were men and 11 were women. The sites included the head of the pancreas $(n=16)$ and the tail of the pancreas $(n=3)$. The mean tumor diameter was $21.7 \pm 6.8 \mathrm{~mm}$ and the numbers of patients with each UICC stage were as follows: IA $(n=1)$; IB $(n=2)$; IIB $(n=9)$; III $(n=4)$; and IV $(n=3)$.

The accuracy of HSP27 detection rate of EUS-FNA samples. When the HSP27 detection rates were compared, the correlation coefficient was $\mathrm{R}=0.61$, which was a statistically significant correlation $(p<0.01)$ (Figure 1).

The comparison between the HSP27 detection rates and the phosphorylated HSP27 detection rates and GEM sensitivity in EUS-FNA samples. Patient background. The background information of all 19 patients is shown in Table II. The mean 


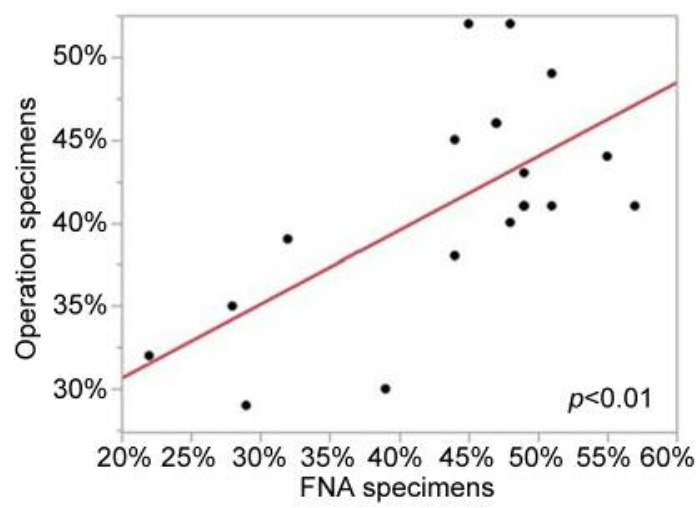

Figure 1. Correlation between the HSP27 detection rates of FNA samples and resected specimens.

Table III. Background of the patients according to the effects of gemcitabine treatment.

\begin{tabular}{lccc}
\hline & $\begin{array}{c}\text { GEM sensitive } \\
\text { group (n=6) }\end{array}$ & $\begin{array}{c}\text { GEM resistant } \\
\text { group (n=13) }\end{array}$ & $p$-Value \\
\hline Gender & & & \\
Male & 2 & 3 & \\
Female & 4 & 10 & n.s. \\
Mean age \pm SD, Y & $66.3 \pm 11.5$ & $70 \pm 7.2$ & n.s. \\
Location & & & \\
Ph & 2 & 3 & \\
Pbt & 4 & 10 & n.s. \\
Tumor size \pm SD, mm & $43.7 \pm 20.9$ & $47.9 \pm 21.1$ & n.s. \\
Metastasis & 3 & & \\
Yes & 3 & 11 & \\
No & & & \\
Performance status & 6 & 10 & \\
0 & 0 & 3 & n.s. \\
1 & & & \\
Secondary treatment & 3 & 4 & \\
Yes & 3 & 9 & n.s. \\
No & $27.6 \pm 21.7$ & $46.1 \pm 23.3$ & n.s. \\
HSP27 (F-4) \pm SD. \% & $13.1 \pm 7.9$ & $31.1 \pm 20.4$ & $p=0.0277$ \\
p-HSP27 (Ser15) \pm SD. \% & $22 \pm 13.6$ & $39.9 \pm 19.9$ & $p=0.0313$ \\
p-HSP27 (Ser78) \pm SD. \% & $30 \pm 24$ & $58.5 \pm 16.9$ & $p=0.004$ \\
p-HSP27 (Ser82) \pm SD. \% & & & \\
\hline
\end{tabular}

age was $69 \pm 8.4$ years and the patients included 5 men and 14 women. The sites, included the head of the pancreas $(n=5)$; and the tail of the pancreas $(n=14)$. The mean tumor diameter was $47.4 \pm 20.7 \mathrm{~mm}$ and organ metastasis was recognized in 14 patients, each of whom was classified as Stage IV (UICC classification, 7th edition). With respect to the effects of GEM treatment, the outcome was SD in 6 patients and PD in 13 patients.

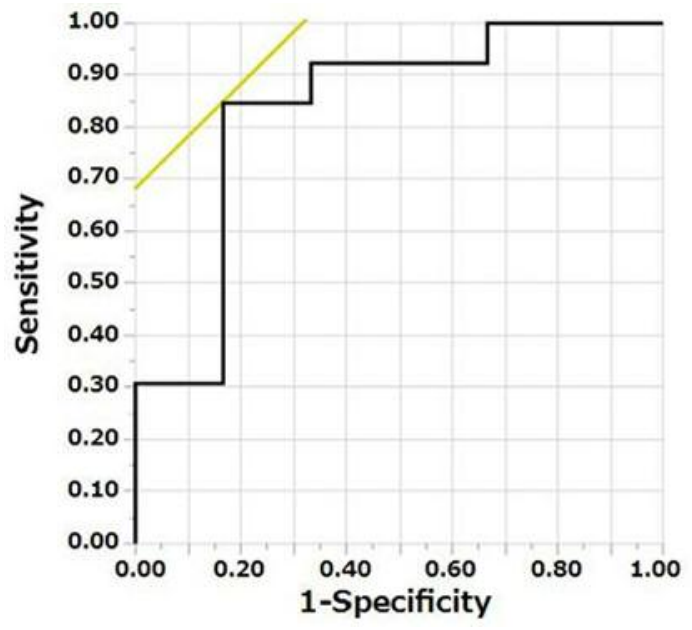

Figure 2. ROC curve analysis for p-HSP27 (Ser82).

Patient backgrounds according to the effect of GEM treatment. The background information of the 19 patients, stratified according to the effect of GEM treatment are shown in Table III. The GEM-sensitive group (SD) included 6 patients (mean age: $66.3 \pm 11.5$ years) and the GEM resistant group (PD) included 13 patients (mean age: $70 \pm 7.2$ ). The male to female ratios were 2:4 in the SD group and 3:10 in the PD group. Regarding the site, the ratios of the head of the pancreas to the tail of the pancreas were 2 to 4 for SD and 3 to 10 for PD. The mean tumor diameter was $43.7 \pm 20.9 \mathrm{~mm}$ for SD and 47.9 \pm 21.1 $\mathrm{mm}$ for PD. The ratios of patients with organ metastasis to those and without organ metastasis were 3 to 3 for SD and 11 to 2 for PD. The ratios of performance status $(0 / 1)$ were 6 to 0 for SD and 10 to 3 for PD. The ratios of patients with second treatment to those without second treatment were 3 to 3 for SD and 4 to 9 for PD. The HSP27 (F-4) detection rates in the SD and PD groups were $27.6 \pm 21.7 \%$ and $46.1 \pm 23.3 \%$, respectively. The pHSP27 (Ser15) detection rates were $13.1 \pm 7.9 \%$ and $31.1 \pm 20.4 \%$, respectively. The p-HSP27 (Ser78) detection rates were $22.0 \pm 13.6 \%$ and $39.9 \pm 19.9 \%$, respectively. The p-HSP27 (Ser82) detection rates were $30.0 \pm 24 \%$ and $58.5 \pm 16.9 \%$, respectively. The p-HSP27 detection rates were significantly high at Ser15, 78 and 82 in the GEM-resistant group $(p<0.05)$.

The HSP27 and p-HSP27 detection rates and the effects of GEM treatment. The details of the HSP27 and p-HSP27 detection rates, the total dose of GEM and the survival period of all 19 patients are shown in Table IV. The optimal cut-off value for detecting GEM sensitivity was divided by the effect of treatment (SD or PD) based on the respective detection rates, and a ROC curve was created. Based on the ROC curve, the cut-off values of HSP27 and p-HSP27 (Ser15,78,82) were 47.3\%, 23.9\%, $34.5 \%$ and $51.6 \%$, respectively; and the area under the curve was $0.71,0.83,0.74$ and 0.83 , respectively (Table V). The greatest 
in vivo $32: 637-642(2018)$

Table IV. HSP27 detection rates, effects of gemcitabine treatment, total doses and survival periods of the 19 patients.

\begin{tabular}{|c|c|c|c|c|c|c|c|}
\hline Case & $\begin{array}{c}\text { Mean HSP27 } \\
(\mathrm{F}-4)\end{array}$ & $\begin{array}{c}\text { Mean pHSP27 } \\
\text { (Ser15) }\end{array}$ & $\begin{array}{c}\text { Mean pHSP27 } \\
(\text { Ser78) }\end{array}$ & $\begin{array}{c}\text { Mean pHSP27 } \\
\text { (Ser82) }\end{array}$ & $\begin{array}{l}\text { Efficacy } \\
\text { of GEM }\end{array}$ & $\begin{array}{l}\text { Total dose } \\
\quad(\mathrm{mg})\end{array}$ & $\begin{array}{l}\text { Survival period } \\
\text { (date) }\end{array}$ \\
\hline 1 & 0 & 5.5 & 23.3 & 0 & SD & 7000 & 319 \\
\hline 2 & 24.2 & 15.9 & 29.1 & 28.3 & SD & 13200 & 190 \\
\hline 3 & 37.2 & 22.5 & 17.2 & 66 & SD & 27200 & 267 \\
\hline 4 & 51.9 & 21.4 & 9.8 & 30.7 & SD & 40600 & 408 \\
\hline 5 & 47.2 & 9.2 & 44.4 & 45.6 & SD & 20400 & 324 \\
\hline 6 & 5.1 & 4.6 & 8 & 9.2 & SD & 47600 & 365 \\
\hline 7 & 13.2 & 32.4 & 15.4 & 41.5 & PD & 3600 & 85 \\
\hline 8 & 24.8 & 34.8 & 30.7 & 62.5 & PD & 4000 & 95 \\
\hline 9 & 19.3 & 23.9 & 12.5 & 51.6 & PD & 3400 & 177 \\
\hline 10 & 51.7 & 47.3 & 35.1 & 64.7 & PD & 1000 & 33 \\
\hline 11 & 47.3 & 25.3 & 44.2 & 51.8 & PD & 4500 & 178 \\
\hline 12 & 60.5 & 30.1 & 47.8 & 61.6 & PD & 2400 & 80 \\
\hline 13 & 68.1 & 65 & 55 & 65 & PD & 5400 & 79 \\
\hline 14 & 66.1 & 75 & 62 & 77.4 & PD & 3600 & 166 \\
\hline 15 & 68.5 & 25 & 57.2 & 78.8 & PD & 6400 & 114 \\
\hline 16 & 88.4 & 55.1 & 76.3 & 69.8 & PD & 2400 & 142 \\
\hline 17 & 31.8 & 0 & 32 & 56.7 & PD & 1000 & 50 \\
\hline 18 & 37.6 & 9.5 & 11.8 & 14 & PD & 5000 & 90 \\
\hline 19 & 22.2 & 6.6 & 38.8 & 66.9 & PD & 4000 & 120 \\
\hline
\end{tabular}

Table V. Comparison of the optimal cut-off values as determined by ROC curve analysis.

\begin{tabular}{|c|c|c|c|c|c|}
\hline & AUC & $\begin{array}{c}\text { Cut off } \\
\text { value }(\%)\end{array}$ & $\begin{array}{c}\text { Sensitivity } \\
(95 \% \mathrm{CI})\end{array}$ & $\begin{array}{c}\text { Specificity } \\
(95 \% \mathrm{CI})\end{array}$ & $\begin{array}{l}\text { Accuracy } \\
(95 \% \mathrm{CI})\end{array}$ \\
\hline $\begin{array}{l}\text { HSP27 } \\
\text { (F-4) }\end{array}$ & 0.71 & 47.3 & $\begin{array}{c}54 \\
(0.25-0.81)\end{array}$ & $\begin{array}{c}83 \\
(0.43-1.00)\end{array}$ & $\begin{array}{c}63.2 \\
(0.44-0.84)\end{array}$ \\
\hline $\begin{array}{l}\text { pHSP27 } \\
\text { (Ser15) }\end{array}$ & 0.83 & 23.9 & $\begin{array}{c}77 \\
(0.62-0.96)\end{array}$ & $\begin{array}{c}100 \\
(0.98-1.00)\end{array}$ & $\begin{array}{c}84.2 \\
(1.10-0.97)\end{array}$ \\
\hline $\begin{array}{l}\text { pHSP27 } \\
\text { (Ser78) }\end{array}$ & 0.74 & 34.5 & $\begin{array}{c}77 \\
(0.62-0.96)\end{array}$ & $\begin{array}{c}83 \\
(0.43-1.00)\end{array}$ & $\begin{array}{c}78.9 \\
(0.85-0.94)\end{array}$ \\
\hline $\begin{array}{l}\text { pHSP27 } \\
\text { (Ser82) }\end{array}$ & 0.83 & 51.6 & $\begin{array}{c}85 \\
(0.90-0.98)\end{array}$ & $\begin{array}{c}83 \\
(0.43-1.00)\end{array}$ & $\begin{array}{c}84.2 \\
(1.10-0.97)\end{array}$ \\
\hline
\end{tabular}

diagnostic accuracy was observed when Ser82 was used, with $85 \%$ sensitivity and $83 \%$ specificity; $82 \%$ of the cases were correctly diagnosed (Table V, Figure 2). When p-HSP27 (Ser82) was used, the survival rate and the rate of patients who continued to receive GEM were analyzed by the Kaplan-Meier method according to detection rate, the group in which $>51.6 \%$ of the tumor cells were positive for p-HSP27 (Ser82) tended to show a lower survival rate and shorter period of GEM administration in comparison to the group in which $<51.6 \%$ of the tumor cells were positive for p-HSP27 (Ser82) (Figures 3 and 4).

\section{Discussion}

EUS-FNA was first reported by Vilmann et al. (10) in 1992. The procedure enables the histopathological diagnosis of masses located in the pancreatic parenchyma. Based on the results of a meta-analysis (11), the diagnostic ability of EUS-FNA for pancreatic cancer is excellent, with $89 \%$ sensitivity and $96 \%$ specificity. In recent years, the immunohistochemical diagnosis of tumors such as gastrointestinal stromal tumors or pancreatic neuroendocrine tumor by EUS-FNA has been established. In the immunohistochemical examination of HSP27 in this study, the comparison of EUS-FNA samples to resected specimens from patients with pancreatic cancer proved that the immunohistological evaluation of HSP27 using EUS-FNA samples was possible because the HSP27 detection rates of the two types of specimens were correlated with each other.

HSP27 is a chaperonin that is induced by heat shock or hypoxia stress and which has multifunctional cytoprotective effects, including antioxidant and anti-inflammatory actions (12). Its functions include improving arteriosclerotic lesions 


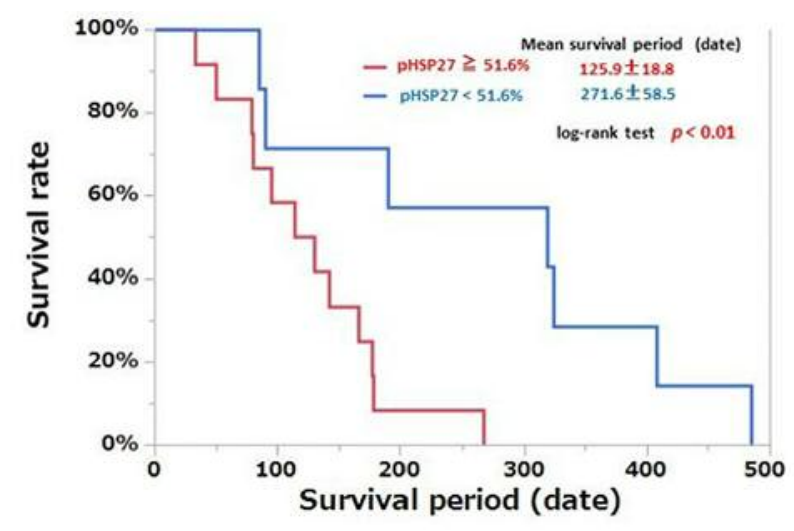

Figure 3. Survival according to the p-HSP27 (Ser82) detection rate.

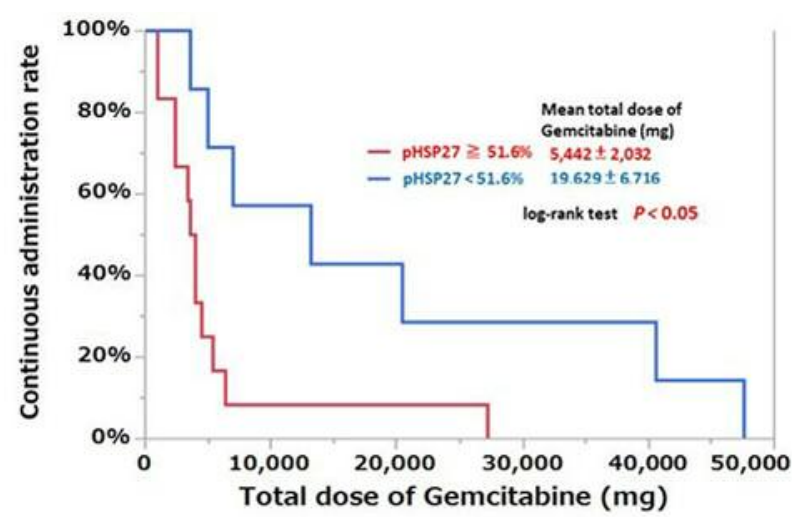

Figure 4. The continuation of GEM administration according to the p-HSP27 (Ser82) detection rate.

(Ser78, Ser82) was more strongly increased than the HSP27 expression in a GEM-resistant pancreatic cancer cell line (8). In this study, p-HSP27 was significantly overexpressed in the GEM resistant group. Especially, when the optimal cut off value of p-HSP27 (Ser82) detection rate was set at 51.6\%, the diagnostic accuracy was good and an association between the p-HSP27 (Ser82) detection rate and the prognosis was suggested. A future study is expected to clarify the molecular biological mechanisms through which p-HSP27 influences GEM resistance.

Recently, because EUS-FNA is a less invasive approach, there has been a gradual increase in reports using EUS-FNA samples $(5,23)$. The ability to predict the effects of a medicine using pretreatment specimen would help in the selection of appropriate chemotherapy regimens for unresectable pancreatic cancer.

\section{Conclusion}

Our evaluation of the HSP27 expression in pancreatic cancer showed a correlation between the HSP27 detection rates of resected specimens and EUS-FNA samples and proved that the HSP27 expression could be evaluated using EUS-FNA samples. The results of the present study suggest that measurement of the HSP27 rate in EUS-FNA samples is useful for predicting GEM sensitivity.

\section{References}

1 Burris HA III, Moore MJ, Andersen J, Green MR, Rothenberg ML, Modiano MR, Cripps MC, Portenoy RK, Storniolo AM, Tarassoff P, Nelsen R, Dorr FA, Stephens CD and Von Hoff DD: Improvements in survival and clinical benefit with gemcitabine as first-line therapy for patients with advanced pancreas cancer: A randomized trial. J Clin Oncol 15: 24032413, 1997. 
2 Conroy T, Desseigne F, Ychau M, Bouche O, Guimbaud R, Becouam Y, Adenis A, Raoul JL, Gourgou-Bourgade S, de la Fouchardiere C, Bennouna J, Bachet JB, Khemissa-Akouz F, PeterVerge D, Delbaldo C, Assenat E, Chauffert B, Michel P, MontotoGrillot $\mathrm{C}$ and Ducreux M: FOLFIRINOX versus gemcitabine for metastatic pancreatic cancer. N Engl J Med 364: 1817-1825, 2011.

3 Von Hoff DD, Ramanathan RK, Borad MJ, Laheru DA, Smith LS, Wood TE, Korn RL, Desai N, Trieu V, Iqlesias JL, Zhang $\mathrm{H}$, Soon-Shiong P, Shi T, Rajeshkumar NV, Maitra A and Hidalgo M: Gemcitabine plus nab-paclitaxel is an active regimen in patients with advanced pancreatic cancer: a phase I/II trial. J Clin Oncol 29: 4548-4554, 2011.

4 Nakahira S, Nakamori S, Tsujie M, Takahashi Y, Okami J, Yoshioka S, Yamasaki M, Marubashi S, Takemasa I, Miyamoto A, Takeda Y, Nagano H, Dono K, Umeshita K, Sakon M and Monden M: Involvement of ribonucleotide reductase M1 subunit overexpression in gemcitabine resistance of human pancreatic cancer. Int J Cancer 120: 1355-1363, 2006.

5 Itoi T, Sofuni A, Fukushima N, Itokawa F, Tsuchiya T, Kurihara T, Moriyasu F, Tsuchida A and Kasuya K: Ribonucleotide reductase subunit 2 mRNA expression in pretreatment biopsies obtained from unresctable pancreatic carcinomas. J Gastroenterol 42: 389-394, 2007.

6 Mori-Iwamoto S, Kuramitsu Y, Ryozawa S, Mikuriya K, Fujimoto M, Maehara S, Maehara Y, Okita K, Nakamura K and Sakaida I: Proteomics finding heat-shock Protein 27 as a biomarker for resistance of pancreatic cancer cells to gemcitabine. Int J Oncol 31: 1345-1350, 2007.

7 Mori-Iwamoto S, Kuramitsu Y, Ryozawa S, Taba K, Fujimoto M, Okita K, Nakamura K and Sakaida I: A proteomic profiling of gemcitabine resistance in pancreatic cancer cell lines. Mol Med Rep 1: 429-434, 2008.

8 Taba K, Kuramitsu Y, Ryozawa S, Yoshida K, Tanaka T, Maehara S, Maehara Y, Nakamura K and Sakaida I: Heat-shock protein 27 is phosphorylated in gemcitabine-resistant pancreatic cancer cells. Anticancer Res 30: 2539-2543, 2010.

9 Eisenhauer EA, Thrasse P, Bogaerts J, Schwartz LH, Sargent D, Ford R, Dancey J, Arbuck S, Gwyther S, Mooney M, Rubinstein L, Shankar L, Dodd L, Kaplan R, Lancombe D and Verweij J: New response evaluation criteria in solid tumours: Revised RECIST guideline (version 1.1). Eur J Cancer 45: 228-247, 2009.

10 Vilmann P, Jacobsen GK, Henriksen FW and Hancke S: Endoscopic ultrasonography with guided fine needle aspiration biopsy in pancreatic disease. Gastrointest Endosc 38: 172-173, 1992.

11 Chen G, Liu S, Zhao Y, Dai M and Zhang T: Diagnostic accuracy of endoscopic ultrasound-guided fine-needle aspiration for pancreatic cancer:a meta-analysis. Pancreatology 13: 298304, 2013.

12 Mymrikov EV, Seit-Nebi AS and Gusev NB: Large potentials of small heat shock proteins. Physiol Rev 91: 1123-1159, 2011.

13 Park HK, Park EC, Bae SW, Park MY, Kim SW, Yoo HS, Tudev M, Ko YH, Choi YH, Kim S, Kim DI, Kim YW, Lee BB, Yoon JB and Park JE: Expression of heat shock protein 27 in human atherosclerotic plaques and increased plasma level of heat shock protein 27 in patients with acute coronary syndrome. Circulation 114: 886-893, 2006.
14 van der Weerd L, Tariq Akbar M, Aron Badin R, Valentim LM, Thomas DL, Wells DJ, Latchman DS, Gardian DG, Lythgoe MF and de Belleroche JS: Overexpression of heat shock protein 27 reduces cortical damage after cerebral ischemia. J Cereb Blood Flow Metab 30: 849-856, 2010.

15 Lambert H, Charette SJ, Bernier AF, Guimond A and Landry J: HSP27 multimerization mediated by phosphorylation-sensitive intermolecular interactions at the amino terminus. J Biol Chem 274: 9378-9385, 1999.

16 Love S and King R: A $27 \mathrm{kDa}$ heat shock protein that has anomalous prognostic powers in early and advanced breast cancer. Br J Cancer 69: 743-748, 1994.

17 Langdon SP, Rabiasz GJ, Hirst GL, King RJ, Hawkins RA, Smyth JF and Miller WR: Expression of the heat shock protein HSP27 in human ovarian cancer. Clin Can Res 1603: 1603-1609, 1995.

18 Ciocca DR, Fuqua SA, Lock-Lim S, Toft DO, Welch WJ and McGuire WL: Response of human breast cancer cells to heat shock and chemotherapeutic drugs. Cancer Res 52: 2648-3654, 1992.

19 Liu QH, Zhao CY, Zhang J, Chen Y, Gao L, Ni CY and Zhu MH: Role of heat shock protein 27 in gemcitabine-resistant human pancreatic cancer: Comparative proteomic analysis. Mol Med Rep 6: 767-773, 2012.

20 Schafer C, Seelinger H, Bader DC, Assmann G, Buchner D, Guo Y, Ziesch A, Palagyi A, Ochs S, Laubender RP, Jung A, De Toni EN, Kirchner T, Goke B, Bruns C and Gallmeier E: Heat shock protein 27 as a prognostic and predictive biomarker in pancreatic ductal adenocarcinoma. J Cell Mol Med 16: 1776-1791, 2012.

21 Benjamin IJ and McMillan DR: Stress (Heat Shock) proteins molecular chaperones in cardiovascular biology and disease. Circ Res 83: 117-132, 1998.

22 Eto D, Hisaka T, Horiuchi H, Uchida S, Ishikawa H, Kawashima Y, Kinugasa T, Nakashima O, Yano H, Okuda K and Akagi Y: Expression of HSP27 in hepatocellular carcinoma. Anticancer Res 36: 3775-3780, 2016.

23 Fujita H, Ohuchida K, Mizumoto K, Itaba S, Ito T, Nakata K, Yu J, Kayashima T, Souzaki R, Tajiri T, Manabe T, Ohtsuka T and Tanaka M: Gene expression levels as predictive markers of outcome in pancreatic cancer after gemcitabine-based adjuvant chemotherapy. Neoplasia 12: 807-817, 2010. 